\title{
THE LIFE CYCLE OF DIPHYLLOBOTHRIUM CORDICEPS (CESTODA: PSEUDOPHYLLIDEA) IN YELLOWSTONE LAKE
}

N. Kingston and Kenneth L. Diem University of Wyoming

\section{Objectives}

Aspects of the life cycle of $\underline{D}$. cordiceps have been known for more than a century, viz., the occurrence of plerocercoids in the secondary intermediate host(s), cutthroat (and other) trout, in Yellowstone National Park (Leidy, 1872); and the development of the adult parasite in various homoithermic definitive hosts (pelican, gull, bear, others) on ingestion of the larval plerocercoids with the flesh of the infected intermediate host (Scott and Honess, 1934). Attempts by various workers to complete the life cycle by incubation and matching of eggs of the tapeworm and infection of the primary intermediate host (presumably some copepod) have been unsuccessful (Crosby, 1970; Post, 1971).

To attempt the elucidation of the unknown aspects of the life cycle of this parasite, it was considered necessary to collect eggs of the parasite, either from feces of one (or more) of the naturally infected definitive hosts or from laboratory infected hosts (e.g., dog, man). The eggs would then be handled and examined, following various incubation strategies, to determine requirements for incubation and hatching in this species. Also, copepods from Yellowstone Lake would be held (and reared) in the laboratory. With successful hatching of the parasite eggs and escape of coracidia (the ciliated, embryonic stage of the parasite) putative primary intermediate hosts would be available for infection experiments.

Of further interest was the identity and bionomics of this parasite. It has been variously denominated Diphyllobothrium cordiceps, D. cordatum, and $D$. latum; other names have also been applied. There is considerable interest in the circumboreal tapeworm species of fishes which often utilize man as well as other warm-blooded hosts in their life-cycles (Rausch and Hilliard, 1970).

\section{Procedures}

Tapeworm eggs were collected by screening (final screen - $54 \mu \mathrm{m}$ ) pelican feces and soil samples taken from the white pelican, Pelecanus erythrorhynchos, rookery on the Molly Islands in the southeast arm of Yellowstone Lake on August 15. Copepods were collected on July $9-10$ and August 11 , using a Wisconsin type plankton net towed $6-8$ in below the surface of the lake in the vicinity of the Molly Islands. Plankton hauls were transported to the laboratory in an ice chest in plastic bags containing lake water and filled with $\mathrm{O}_{2}$. Tapeworm eggs being held for incubation and hatching, as well as, copepods were maintained in lake water at laboratory room temperatures of 
$20-21^{\circ} \mathrm{C}$ and lake water temperatures of $5-7^{\circ} \mathrm{C}$ (Mueller, 1970).

Cutthroat trout were collected with hook and line on both trips in the vicinity of the Molly Islands to determine the extent of their infections with tapeworms, the tapeworm species present and the tissue site of the infection. Live tapeworm parasites (plerocercoids) from the fish were transported, refrigerated in situ or in vitro in saline for infection studies. In the laboratory, some adutt and Tarval tapeworms were relaxed in hot water $\left(140^{\circ} \mathrm{F}\right)$ and fixed in $10 \%$ formalin for study as whole or sectioned mounts.

$\underline{\text { Results }}$

Tapeworms recovery data from necropsied cutthroat trout are summarized in Table 1. During the August 15 trip a very recently deceased juvenile pelican was necropsied and the viscera were removed. In the laboratory a number of gravid proglottids, as well as free eggs were recovered from the tract fecal material. Eight live, adult tapeworms were recovered from the intestine of the same digestive tract. Gravid (egg containing) terminal proglottids were identified, cut from the remainder of the strobila and stored at $4^{\circ} \mathrm{C}$ in lake water. The remainder of the tapeworms from the pelican and some of the worms from the fish were relaxed and fixed for whole and section mounts.

From the remaining larval tapeworms, 14 were swallowed in capsules by the senior author. No eggs have been found in his feces, thus far. Also, 16 plerocercoids were fed to a mixed-breed canine. No eggs have been recovered from this putative host to date. Ten plerocercoids were fed (by stomach tube) to a laboratory-reared cutthroat maintained in the Wyoming Game and Fish Department Research Laboratory. When this fish died 2 months later, 9-10 worms were recovered: 1 (or 2) in the stomach wall; 4 in cysts on the pyloric caeca; 2 in the body cavity; and 2 had reached the retroperitoneal musculature. Some tissue and worms of this fish were fixed and four worms were fed ( $v i a$ stomach tube) to another laboratory-reared trout. Indeed tapeworms are immortal!

Tapeworm eggs (from pelican feces or dissected proglottids and stored for 1 month at $4^{\circ} \mathrm{C}$ ) were placed in lake water in four $125 \mathrm{ml}$ Ehrlenmeyer flasks. These flasks were stoppered with appropriate air exhaust and intake valves, supplied with pumped air and agitated $(180-190$ rotations $/ \mathrm{min})$ at $5-7^{\circ} \mathrm{C}$ or $20-21^{\circ} \mathrm{C}$. Unfortunately, the refrigeration system for the eggs at $5-7^{\circ} \mathrm{C}$ failed at 14 days. The incubation flasks from that specific treatment were exposed to room temperatures where incubation was completed and hatching occurred. Thus, no comparisons of incubation times at the two temperatures could be made at this time.

Coracidia were hatched from the tapeworm eggs at 18-21 days. During this period eggs and coracidia were photographed. Copepods ( $\mathrm{Ca} 24$ ) were introduced into the flasks where tapeworm eggs were hatching. Subsequent examination 12-14 days later revealed no infections in those putative hosts. The collected population of copepods has thus far been successfully maintained in the laboratory. Further studies with massive numbers of hatched coracidia (from stored eggs) using laboratory-reared copepods are about to be undertaken. 


\section{Conclusions}

Eggs can be collected from feces or proglottids from definitive hosts. Incubation times are short (18-21 days) and hatched coracidia appear normal. Infection can be transferred from one fish host to another by feeding (stomach-tube) plerocercoids, thus allowing a source of infected second intermediate hosts in the laboratory. Copepods can be held at room temperatures and at $5-7^{\circ} \mathrm{C}$ for extended periods. No conclusions can be drawn from infection experiments in humans and dogs.

\section{Acknowledgments}

We would like to thank Mr. Roger Rudolph, South District Ranger, Mr. John Scott, Seasonal Park Ranger, Yellowstone National Park and Mr. Samuel Zeveloff, University of Wyoming, for aid in conducting these studies.

\section{Literature Cited}

Crosby, C. W. 1970. Studies on the life cycle of Diphyllobothrium cordiceps. Unpub. M.S. Colo. State Univ.

Leidy, J. 1872. Notice of some worms collected during Prof. Hayden's expedition to the Yellowstone River in the summer of 1871. U.S. Geol. Survey of Montana and adjacent territories, Hayden.

Mueller, J. F. 1959. The laboratory propagation of Spirometra mansonoides as an experimental tool. I. Collecting, incubation and hatching of the eggs. J. Parasit. 45: 353-361.

Post, G. 1971. The Diphyllobothrium cestode problem in Yellowstone Lake, Wyoming. Univ. of Wyo. Agric. Exp. Stat. Bull. \#51.

Rausch, R. L. and D. K. Hilliard. 1970. Studies on the helminth fauna of Alaska. XLIX. The occurrence of Diphyllobothrium latum (Linnaeus, 1758) (Cestoda:Diphyllobothriidae) in Alaska, with notes on other species. Can. Jour. Zool. 48: 1200-1209.

Scott, J. W. and R. Honess. 1934. Results from feeding plerocercoids from Salmo lewisi. Colo.-Wyo. Acad. Sci. I(6): 76-77. 
Table 1. Cutthroat trout examined for larval Diphyllobothrium cordiceps.

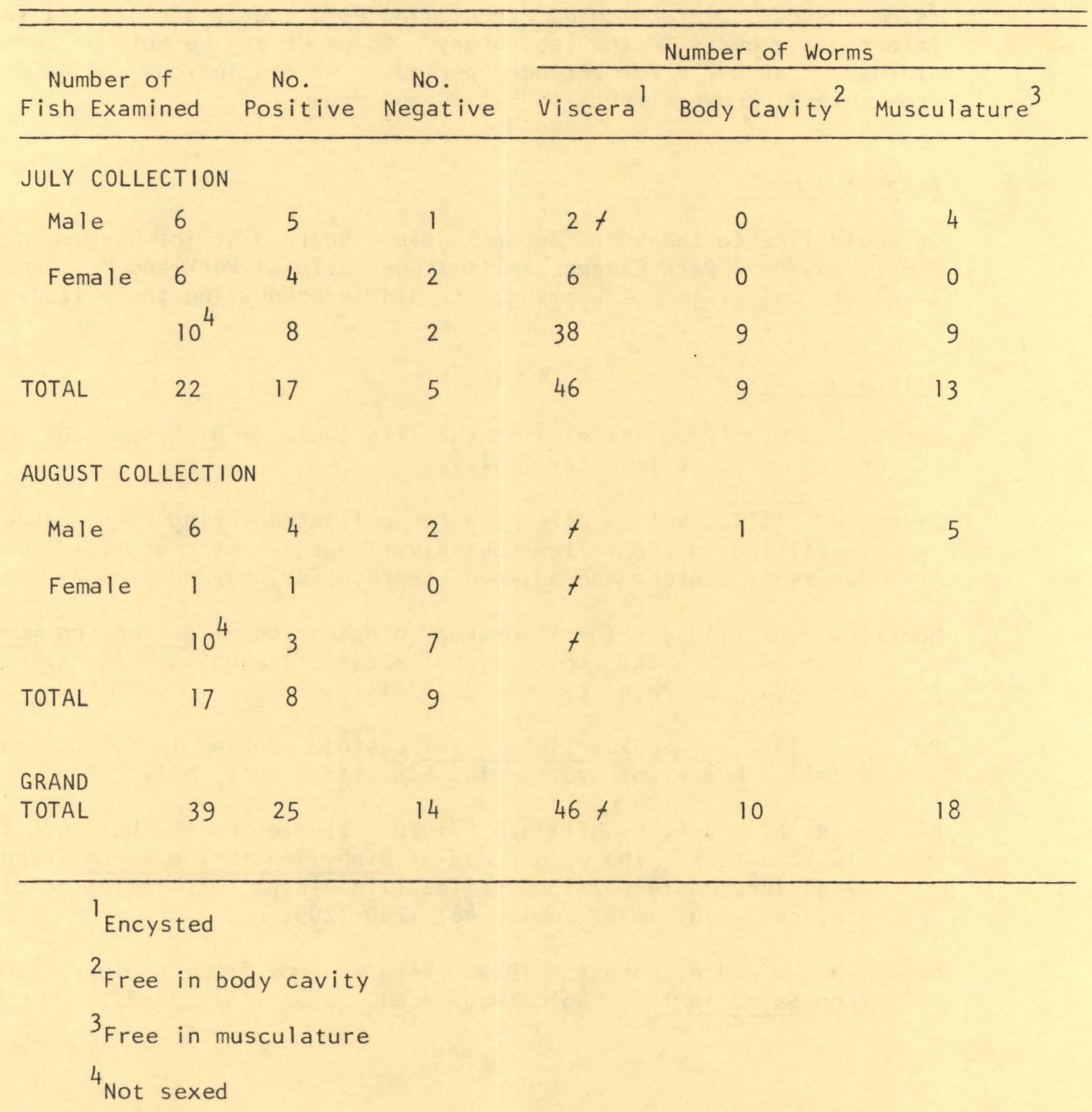

